\title{
Avaliação do uso de argilas montmorilonitas modificadas na adsorção de nitrato em meio aquoso
}

\author{
Evaluation of nitrate adsorption from \\ aqueous medium using modified montmorillonites \\ lara Jennifer Moura Duarte ${ }^{1} \odot$, Alinne Joyce Rocha Soares ${ }^{1} \odot$,

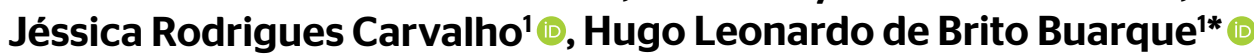

口

\section{RESUMO}

Este estudo investigou a eficiência da remoção de nitrato em meio aquoso usando adsorção em argilas montmorilonitas comerciais, comparativamente a uma resina aniônica comumente usada nessa operação. Algumas dessas argilas foram intercaladas como o ín hexadeciltrimetilamônio para avaliação. Áreas superficiais específicas, capacidades de troca catiônica e espectros de infravermelho médio foram obtidos para caracterização das argilas. Testes preliminares indicaram a nanoargila funcionalizada com aminopropiltrietoxisilano e octadecilamina como a mais eficiente na adsorção de nitrato, conquanto não tenha superado em eficiência a resina aniônica comercial também testada. Curvas cinéticas e isotermas de equilíbrio de adsorção de nitrato em fase aquosa na nanoargila e na resina comercial foram determinadas e modeladas para comparação, como também para seleção de modelos representativos e para estimativa de propriedades termodinâmicas dos sistemas estudados. Todos os ensaios foram realizados a $25^{\circ} \mathrm{C}$ e com $\mathrm{pH}$ neutro. Isotermas de equilibrio também foram determinadas a 35 e $45^{\circ} \mathrm{C}$. Os resultados obtidos mostram que o processo adsortivo estudado é físico, espontâneo e favorável tanto para a resina como para a nanoargila, as quais possuem muito boa afinidade com o nitrato. O modelo mais representativo para a cinética foi o de pseudossegunda ordem, enquanto para o equilíbrio foi a isoterma de Freundlich.

Palavras-chave: argila funcionalizada; manancial contaminado; adsorção em fase aquosa.

\begin{abstract}
This study investigated the efficiency of nitrate removal in aqueous medium using adsorption on commercial montmorillonites compared to an anionic resin widely used in this operation. Some of these clays were intercalated with hexadecyltrimethylammonium ion for this investigation. Specific surface areas, cation exchange capacities and mid-infrared spectra were determined for clays characterization. Preliminary tests indicated that the nanoclay functionalized with aminopropyltriethoxysilane and octadecylamine was the most efficient in nitrate adsorption, although it did not exceed anionic resin in efficiency. Adsorption kinetic and equilibrium of nitrate from aqueous phase on the nanoclay and anionic resin were determined and modeled for comparison, as well as for the selection of representative models and estimation of thermodynamic properties of the studied systems. All experiments were carried out at $25^{\circ} \mathrm{C}$ and at $\mathrm{pH}$ 7. Equilibrium isotherms were also determined at 35 and $45^{\circ} \mathrm{C}$. The obtained results show that the adsorption processes studied are physical, spontaneous and favorable for both the resin and the nanoclay, which have very good affinity with nitrate. The most representative models for the systems were the pseudo-second order kinetic model and the Freundlich equilibrium isotherm
\end{abstract}

Keywords: functionalized clay; contaminated supply source; aqueous adsorption

\section{INTRODUÇÃO}

A qualidade das águas está cada vez mais comprometida em decorrência da intensificação das ações antrópicas com o passar dos anos, as quais têm contribuído significativamente para a contaminação de mananciais por diferentes poluentes, entre eles o nitrato (GOMES; BARIZON, 2014; TORRES, 2011). Particularmente, a contaminação de mananciais por nitrato gera uma diversidade de impactos negativos dos pontos de vista sanitário, ambiental e econômico (MILMILE et al., 2011). Essa realidade é uma preocupação crescente das companhias de saneamento ambiental, em razão do potencial contaminante desse íon e dos aspectos legais e econômicos associados (AGUIAR; SANTIAGO, VASCONCELOS, 2000; COSTA et al., 2012; FREITAS; SALES, 2014).

Portanto, a busca por técnicas de tratamento de mananciais contaminados por nitrato é de grande importância científica e tecnológica,

\section{$\square$}

IInstituto Federal de Educação, Ciência e Tecnologia do Ceará - Fortaleza (CE), Brasil. *Autor correspondente: hbuarque@ifce.edu.br

Recebido: 09/08/2016 - Aceito: 14/09/2017 - Reg. ABES: 167642 
particularmente pela difícil remoção desse contaminante por meio de tecnologias comumente utilizadas nas estações de tratamento de água, como a filtração (HARO, 2011). Nesse contexto, a adsorção se destaca como uma das técnicas mais promissoras para a remoção seletiva de diversos contaminantes em água, haja vista que em muitos estudos se apresenta como uma técnica efetiva, econômica, versátil e simples (SHARMA et al., 2011).

Entre tantos adsorventes avaliados para a remoção de contaminantes de solução aquosa, a montmorilonita tem chamado a atenção por ser relativamente barata, de fácil obtenção e por suas capacidades de adsorção tipicamente elevadas (VIMONSES et al., 2009; BHARDWAJ et al., 2012). As propriedades superficiais dessa argila podem ser modificadas, atribuindo características mais apropriadas para adsorção de diferentes tipos de espécies químicas a esse material, inclusive certos ânions e compostos orgânicos (SANTOS, 1989). Nesse contexto, diversos estudos têm comprovado a eficácia das argilas montmorilonitas modificadas na adsorção de nitrato (BAGHERIFAM et al., 2014; LI; LI; MENG, 2010; XI; MALLAVARAPU; NAIDU, 2010; BHARDWAJ et al., 2012; SELIEM et al., 2013; MENA-DURAN et al., 2007; BEKELE; FAYE; FERNANDEZ, 2014).

Assim, as argilas modificadas podem representar uma alternativa viável e de baixo custo para o tratamento de mananciais contaminados por nitrato. Dessa forma, este estudo avaliou o potencial de argilas montmorilonitas comerciais na remoção por adsorção de nitrato em meio aquoso, sob condições ambientes e $\mathrm{pH}$ neutro. Dados cinéticos e isotermas foram determinados e modelados para a adsorção de nitrato na argila melhor avaliada. Os mesmos dados também foram obtidos para uma resina de troca iônica, comercialmente usada na remoção de nitrato, para fins de comparação com as argilas avaliadas.

\section{MATERIAIS E MÉTODOS}

\section{Materiais utilizados}

Duas argilas modificadas comerciais foram utilizadas neste estudo: uma montmorilonita acidificada K 10 (MK10) e uma nanoargila funcionalizada (MAO) com aminopropiltrietoxisilano (0,5-5\%) e octadecilamina (15-35\%), ambas da marca Aldrich.

Outras duas argilas comerciais, constituídas predominantemente de montmorilonitas sódicas, foram utilizadas nos ensaios adsortivos: uma bentonita natural Creme (BCN) e uma bentonita natural Fungel (BFN), que foram gentilmente cedidas pela Brasil Minas Ltda e pela Empresa Brasileira de Minérios Ltda, respectivamente. Ressalte-se que essas bentonitas foram ensaiadas tanto na sua forma natural como modificada com um sal quaternário de amônio: o brometo de hexadeciltrimetilamônio (HDTMA). Ainda, uma quinta montmorilonita modificada também foi avaliada neste estudo, obtida a partir da intercalação do cátion do HDTMA na argila MK10.
Adicionalmente, de modo a servir de referência na determinação da viabilidade do uso das argilas testadas no processo de tratamento de águas com teores indesejáveis de nitrato, uma resina de troca aniônica comercial A520E (RAC), da marca Purolite, com especificação de umidade de 50\%, usada industrialmente para tratar águas contaminadas por nitrato, foi avaliada na remoção desse ânion.

\section{Modificação das argilas naturais e da argila montmorilonita acidificada $\mathrm{K} 10$}

As bentonitas naturais (Creme e Fungel) e a MK10 foram modificadas superficialmente com o HDTMA, com o intuito de melhorar sua capacidade de adsorção de nitrato, produzindo argilas aqui denominadas bentonita Creme modificada (BCM), bentonita Fungel modificada (BFM) e MK10 modificada (MKM).

As modificações foram realizadas seguindo adaptações das metodologias de Bhardwaj et al. (2012), na obtenção da BCM e da BFM, e de Bagherifam et al. (2014), na produção da MKM. Dessa forma, as bentonitas naturais foram modificadas utilizando solução de HDTMA com concentração que levou em consideração a capacidade de troca catiônica (CTC) dessas argilas. Nesse procedimento, $5 \mathrm{~g}$ das argilas a serem modificadas foram misturados com solução alcoólica de HDTMA; a mistura foi agitada, a $70^{\circ} \mathrm{C}$, em câmara incubadora por 48 horas, depois centrifugada por 15 minutos (2.000 rpm) e lavada vigorosamente em solução água-etanol 1:1, até remoção de todo o sal quaternário. Finalmente, foi filtrada e seca sob vácuo a $60^{\circ} \mathrm{C}$ por 24 horas.

\section{Caracterização das argilas}

A determinação da CTC das argilas a serem modificadas, com o intuito de calcular as concentrações da solução do sal de intercalação, como também da argila MAO, foi conduzida por meio de ensaios de adsorção de azul de metileno (método da mancha), baseados no procedimento citado por Yukselen e Kaya (2008). As áreas superficiais específicas (ASE) dessas argilas também foram determinadas pelo método da mancha com azul de metileno (SANTAMARINA et al., 2002; YUKSELEN; KAYA, 2008).

Ainda, espectrogramas de infravermelho médio (4.000-400 $\left.\mathrm{cm}^{-1}\right)$ também foram determinados para todas as argilas avaliadas, em espectrofotômetro FTIR, marca Shimadzu modelo IRAffinity-1, utilizando o método da pastilha de KBr. A análise dos espectrogramas obtidos buscou confirmar os grupos funcionais superficiais esperados para os argilominerais investigados, inclusive aqueles que constatariam a intercalação do cátion do HDTMA nas argilas modificadas com esse sal.

\section{Quantificação do nitrato nos experimentos}

A determinação da concentração inicial ou residual de nitrato nos ensaios realizados foi conduzida por espectrofotometria de absorção molecular no ultravioleta $(220 \mathrm{~nm})$, seguindo o método $4500-\mathrm{NO}_{3}$ - B disponível 
em Eaton et al. (2005), utilizando cubeta de quartzo de $1 \mathrm{~cm}$ de caminho ótico e espectrofotômetro da marca Shimatzu, modelo UV1602PC.

É importante mencionar que todas as amostras, alíquotas e soluções de referência a serem quantificadas, em termos de nitrato, foram previamente centrifugadas a $2.000 \mathrm{rpm}$ por 15 minutos e depois filtradas em filtro para seringa (porosidade de $0,45 \mu \mathrm{m}$ ).

\section{Estudos de adsorção}

Inicialmente, testes preliminares de adsorção foram realizados a fim de verificar a efetividade da remoção de nitrato com as argilas naturais e modificadas consideradas neste estudo e com a resina de troca iônica. A partir da seleção da melhor argila nesses testes, dados fundamentais de adsorção (cinética, equilíbrio e termodinâmica) foram determinados em ensaios batelada.

\section{Testes preliminares de adsorção}

Os testes preliminares de adsorção foram realizados a fim de verificar a viabilidade da remoção de nitrato com as argilas estudadas comparativamente à remoção obtida com a operação de troca iônica, utilizando a RAC, e selecionar a melhor argila entre as avaliadas.

Nesses ensaios, massas preestabelecidas das argilas (150 e $200 \mathrm{mg}$ ), previamente secas em estufa durante 24 horas, ou da resina úmida avaliada (300 e $400 \mathrm{mg}$ ) foram adicionadas em distintos frascos erlenmeyer de $250 \mathrm{~mL}$. A umidade média da RAC foi de $50 \%$.

Em seguida, $40 \mathrm{~mL}$ de solução de nitrato com concentração de $20 \mathrm{mg} \mathrm{N}-\mathrm{NO}_{3} \mathrm{~L}^{-1}\left(88,6 \mathrm{mg} \mathrm{NO}_{3} \mathrm{~L}^{-1}\right)$, com valor de $\mathrm{pH}$ previamente ajustado a 7,0 com soluções de $\mathrm{NaOH}$ ou $\mathrm{HCl}$, foram adicionados aos erlenmeyers. Esses frascos, após serem hermeticamente fechados, foram imediatamente dispostos em banho-maria metabólico com agitação orbital tipo Dubnoff, mantido em temperatura ambiente $\left(25 \pm 2^{\circ} \mathrm{C}\right)$ por 72 horas (tempo estimado superior ao tempo de equilíbrio do processo), após o qual as suspensões de argila foram analisadas para quantificação do residual de nitrato, segundo metodologia previamente descrita, e dos percentuais de remoção desse ânion. Todos os ensaios foram realizados em duplicata ou triplicata. Ressalte-se que a concentração de

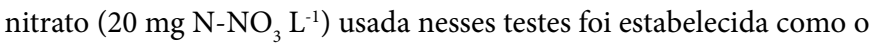
dobro do valor permitido às águas doces que podem ser destinadas ao consumo humano (BRASIL, 2011), de modo a avaliar condições mais extremas que as previstas na legislação para a contaminação de águas naturais por nitrato.

A argila a ser selecionada para os estudos mais detalhados do processo adsortivo foi aquela que apresentou as maiores remoções de nitrato nesses ensaios preliminares.

\section{Determinação do efeito da dosagem do adsorvente}

A avaliação do efeito da dosagem do adsorvente tem por objetivo verificar se, com o aumento da dosagem do adsorvente, é possível remover o poluente em níveis aceitáveis de acordo com a legislação pertinente (NASCIMENTO et al., 2014).

Neste estudo, o efeito da dosagem do material adsorvente foi avaliado em ensaios adsortivos, nos quais as massas da argila selecionada variaram de 50 a $300 \mathrm{mg}$, em intervalos de $50 \mathrm{mg}$, e para os quais as massas da resina variaram de 100 a $600 \mathrm{mg}$, em intervalos de $100 \mathrm{mg}$, que em uma base seca correspondem às mesmas massas de argila. Essas massas foram adicionadas a $40 \mathrm{~mL}$ de uma solução de nitrato de sódio, cuja concentração inicial é de $20 \mathrm{mg} \mathrm{N}-\mathrm{NO}_{3} \mathrm{~L}^{-1} \mathrm{com} \mathrm{pH}$ 7,0 ajustado com hidróxido de sódio e/ou ácido clorídrico. É válido mencionar que a concentração final do adsorvente no meio variou de 1,25 a 7,5 $\mathrm{g} \mathrm{L}^{-1}$.

As células de adsorção foram mantidas na temperatura de $25 \pm 2^{\circ} \mathrm{C}$ e na agitação de 240 rpm durante 24 horas. Então, alíquotas foram retiradas e os teores residuais de nitrato quantificados, segundo metodologia já descrita, e usados no cálculo dos correspondentes percentuais de remoção. A partir dos resultados desses ensaios, foram determinadas as massas da argila selecionada e da RAC nos demais experimentos adsortivos (cinética e equilíbrio).

\section{Curvas cinéticas de adsorção}

Os ensaios cinéticos foram realizados em modo batelada utilizando como base a metodologia apresentada em Sousa Neto (2012).

Assim, em cada célula experimental foi adicionada uma massa $\left(\mathrm{m}_{\mathrm{ads}}\right)$, predeterminada nos testes de efeito da dosagem, da argila selecionada (nos testes preliminares) ou de RAC. Em seguida, a massa adicionada foi colocada em contato por 24 horas com $20 \mathrm{~mL}$ de água bidestilada, cujo $\mathrm{pH}$ foi previamente ajustado para valor 7,0 com solução $0,1 \mathrm{~mol} / \mathrm{L}$ de hidróxido de sódio ou de ácido clorídrico. Após esse tempo, $20 \mathrm{~mL}$ de solução aquosa sintética de nitrato ( $\left.40 \mathrm{mg} \mathrm{N}-\mathrm{NO}_{3} \mathrm{~L}^{-1}\right)$ foram acrescentados à célula, de modo que o volume final $(\mathrm{V})$ na célula e a concentração inicial $\left(\mathrm{C}_{\mathrm{o}}\right)$ de nitrato no meio fossem $40 \mathrm{~mL}$ e $20 \mathrm{mg} \mathrm{N}-\mathrm{NO}_{3} \mathrm{~L}^{-1}$, respectivamente. As células foram, então, agitadas em banho metabólico Dubnoff (Marca Marconi, modelo MA-095) a $240 \mathrm{rpm}$ em temperatura ambiente $\left(25 \pm 2^{\circ} \mathrm{C}\right)$. Após intervalos predefinidos de tempo $(\mathrm{t})$, o teor residual de nitrato $(\mathrm{C})$ nas células foi determinado como já descrito anteriormente (reportada em $\mathrm{mg} \mathrm{NO}_{3} \mathrm{~L}^{-1}$ ), e a quantidade (q) adsorvida em um dado intervalo de tempo, em $\mathrm{mg} \mathrm{NO}_{3} \mathrm{~L}^{-1}$, foi calculada por meio de um balanço de massa expresso na Equação 1. Todos os ensaios foram realizados em duplicata.

$q=\frac{\left(C_{o}-C\right) V}{m_{a d s}}$

As curvas cinéticas obtidas ajustaram um modelo de pseudoprimeira ordem (PPO), proposto por Lagergren (1898) e expresso na Equação 2, e um de pseudossegunda ordem (PSO), proposto por Ho e McKay (1999) e mostrado na Equação 3, de modo a selecionar o mais adequado na representação da taxa de adsorção, dq/dt, dos sistemas 
estudados, a partir de critérios estatísticos: os maiores valores de coeficientes de determinação $\left(R^{2}\right)$ e os menores valores de desvios relativos médios $\left(\Delta_{\mathrm{r}}\right)$ determinados para os ajustes realizados. Os coeficientes determinados no ajuste dos modelos, as constantes de velocidade $k_{1} \mathrm{e}$ $k_{2}$ e os teores $q_{e, 1}$ e $q_{e, 2}$ de nitrato sorvido no equilíbrio, também foram usados na comparação entre os dois materiais em relação à remoção de nitrato em meio aquoso. Os índices 1 e 2 nos coeficientes correspondem, respectivamente, aos modelos de PPO e de PSO.

$\frac{d q}{d t}=k_{1}\left(q_{e, 1}-q\right)$

$\frac{d q}{d t}=k_{2}\left(q_{e, 2}-q\right)^{2}$

O tempo necessário ao equilíbrio também foi avaliado nesses ensaios.

\section{Isotermas de adsorção}

As isotermas de adsorção de nitrato na argila selecionada e na RAC, nas temperaturas 25,35 e $45^{\circ} \mathrm{C}$, foram determinadas seguindo-se o mesmo procedimento e nas mesmas condições de $\mathrm{pH}$ do meio, agitação e concentração dos adsorventes usadas nos testes cinéticos. Contudo, as concentrações iniciais de nitrato nos ensaios variaram

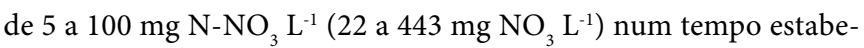
lecido de equilíbrio de 2 horas (determinado nos estudos cinéticos). Todos os experimentos foram realizados em duplicata. A concentração residual de nitrato em equilíbrio $\left(\mathrm{C}_{e}\right)$ nas células foi determinada conforme metodologia analítica já descrita. A concentração de nitrato adsorvido no equilíbrio $\left(\mathrm{q}_{e}\right)$ foi calculada por meio da Equação 1, em que a concentração residual de nitrato em solução é a concentração em equilíbrio. Os teores de nitrato residual em solução e adsorvido no equilíbrio foram expressos, respectivamente, em mg NO${ }_{3} \mathrm{~L}^{-1}$ e em $\mathrm{mg} \mathrm{NO}_{3} \mathrm{~g}^{-1}$.

As isotermas de equilíbrio determinadas ajustaram os dois modelos de equilíbrio de adsorção mais empregados (NASCIMENTO et al., 2014): o modelo de isoterma de Freundlich (MIF), proposto em 1906 e mostrado na Equação 4, e o modelo de isoterma de Langmuir (MIL), proposto em 1916 e expresso na Equação 5, com vistas a selecionar o mais adequado na representação do equilíbrio dos sistemas estudados, a partir de critérios estatísticos: os maiores valores de $\mathrm{R}^{2}$ e os menores valores de $\Delta_{\mathrm{r}}$ determinados para os ajustes realizados nessa etapa.

$q_{e}=\frac{q_{m} k_{L} C_{e}}{1+k_{L} C_{e}}$

$q_{e}=k_{F} C_{e}{ }^{1 / n}$

Os coeficientes determinados no ajuste dos modelos - a capacidade máxima de adsorção em monocamada $\left(\mathrm{q}_{m}\right)$ e a constante de afinidade $\left(\mathrm{k}_{L}\right)$ da isoterma de Langmuir; e os coeficientes empíricos, $\mathrm{k}_{F}$ e $\mathrm{n}$, da isoterma de Freundlich - também podem ser usados na avaliação do processo adsortivo estudado.

O coeficiente $\mathrm{q}_{\mathrm{m}}$ fornece uma estimativa da capacidade de cobertura superficial específica do adsorvente pelo adsorvato, enquanto a constante $\mathrm{k}_{\mathrm{L}}$ indica quão forte é a interação adsorvato-adsorvente (DO, 1998; NASCIMENTO et al., 2014). O coeficiente $\mathrm{k}_{\mathrm{F}}$ também está relacionado com a capacidade de adsorção do adsorvente, ao passo que a constante $\mathrm{n}$ indica se o processo adsortivo é favorável $(\mathrm{n} \geq 1)$ ou desfavorável ( $\mathrm{n}$ < 1) (HAMEED; AHMAD; AZIZ, 2007; NASCIMENTO et al., 2014).

Adicionalmente, os valores da constante de afinidade de Langmuir foram assumidos iguais aos valores da constante de equilíbrio de adsorção dos sistemas nas correspondentes temperaturas e utilizados na estimativa dos seguintes parâmetros termodinâmicos de adsorção (PINHEIRO et al., 2013; HE et al., 2010): variação de entalpia padrão $\left(\Delta \mathrm{H}^{\circ}\right)$, variação de entropia padrão $\left(\Delta \mathrm{S}^{\circ}\right)$ e variação de energia livre de Gibbs padrão $\left(\Delta \mathrm{G}^{\circ}\right)$, por meio das Equações 6 e 7. O fator R na Equação 6 é a constante dos gases ideais, cujo valor é 8,314 $\mathrm{J} \mathrm{K}^{-1} \mathrm{~mol}^{-1}$ no sistema internacional de unidades, e a variável $\mathrm{T}$, em ambas as equações, é a temperatura termodinâmica do sistema, dada em kelvin nesse mesmo sistema de unidades.

$\Delta G^{\circ}=-R T \operatorname{Ln}\left(k_{L}\right)$

$\Delta G^{\circ}=\Delta H^{\circ}-T \Delta S^{\circ}$

Os valores estimados desses parâmetros termodinâmicos podem ser usados para avaliar a espontaneidade do processo, bem como a intensidade das interações entre o nitrato e os adsorventes.

\section{RESULTADOS E DISCUSSÃO}

\section{Caracterização dos adsorventes}

Os dados de ASE e de CTC para as argilas BCN, BFN, MK10 e MAO utilizadas estão apresentados no gráfico da Figura 1.

As bentonitas sódicas apresentaram valores mais elevados de área superficial e de capacidade de troca de cátions que aqueles obtidos para as montmorilonitas MK10 e MAO. A maior CTC na BCN se deve aos mais elevados teores de sódio nesse argilomineral (CARVALHO; BERTAGNOLLI; SILVA, 2009; DUARTE-NETO et al., 2014; PAIVA; MORALES; DÍAZ, 2008; PATRÍCIO, 2013), enquanto os menores valores para a MAO se devem aos grupos organofílicos de sua estrutura, aos quais normalmente é atribuída uma diminuição da CTC e da área superficial (MORITA; BARBOSA; KLOSS, 2015; PAIVA; MORALES; DÍAZ, 2008). 
É importante mencionar que a ASE de $454 \mathrm{~m}^{2} \mathrm{~g}^{-1}$, determinada pelo método da mancha com azul de metileno para a argila MK10, é bem superior ao valor de área superficial BET (220 a $270 \mathrm{~m}^{2} \mathrm{~g}^{-1}$ ) informado pelo fornecedor, já que o método da mancha, realizado em fase aquosa, contabiliza também a área superficial interna da argila ao promover a troca catiônica com o corante, enquanto a técnica BET só mensura a área superficial externa do material argiloso (SANTAMARINA et al., 2002; YUKSELEN; KAYA, 2008). O valor de CTC obtido para a MK10 também foi relativamente menor que os valores reportados na literatura, variando na faixa entre $80 \mathrm{e}$ $120 \mathrm{meq}(100 \mathrm{~g})^{-1}$ para esse tipo de argila (PEREIRA, 2014). Contudo, como sugere Heller-Kallai (2001), a composição química da montmorilonita pode influenciar sua CTC, e normalmente varia consideravelmente, mesmo em um mesmo depósito de extração. Como já mencionado, os valores de CTC determinados para as argilas $\mathrm{BCN}$, BCM e MK10 foram usados no cálculo da concentração da solução de HDTMA na etapa de modificação dessas argilas.

Os espectros de infravermelho determinados em termos de transmitância para todas as argilas preliminarmente consideradas estão mostrados na Figura 2.

As bandas peculiares à montmorilonita são observadas para todas as amostras na região entre 1.000 e $1.100 \mathrm{~cm}^{-1}$ (típicas das ligações Si-O-Si) e em 917, 797 e $525 \mathrm{~cm}^{-1}$, decorrentes das camadas octaédricas dos aluminossilicatos presentes. Uma banda próxima de $3.626 \mathrm{~cm}^{-1}$, atribuída às vibrações de estiramento do grupo estrutural hidroxílico próprio desse grupo de argilas, também pode ser observada nos espectros obtidos. Ainda, pode-se notar uma banda na região entre 3.400 e $3.465 \mathrm{~cm}^{-1}$, típica de vibrações de estiramento do grupo $\mathrm{OH}$ referente à água adsorvida presente em argilas. É interessante observar que as bandas próximas de $2.850 \mathrm{e}$ $2.920 \mathrm{~cm}^{-1}$, características dos modos de vibração simétrico e assimétrico do grupo $\mathrm{CH}_{2}$, estão bem destacadas nas argilas modificadas neste estudo e são maiores ainda na MAO, sugerindo maior quantidade dos grupos organofílicos nessa última argila. As bandas observadas entre 1.470 e $1.500 \mathrm{~cm}^{-1}$ indicam a presença de vibrações
C-N em aminas terciárias, corroborando a modificação de superfície nas argilas BCM, BFM, MKM e MAO.

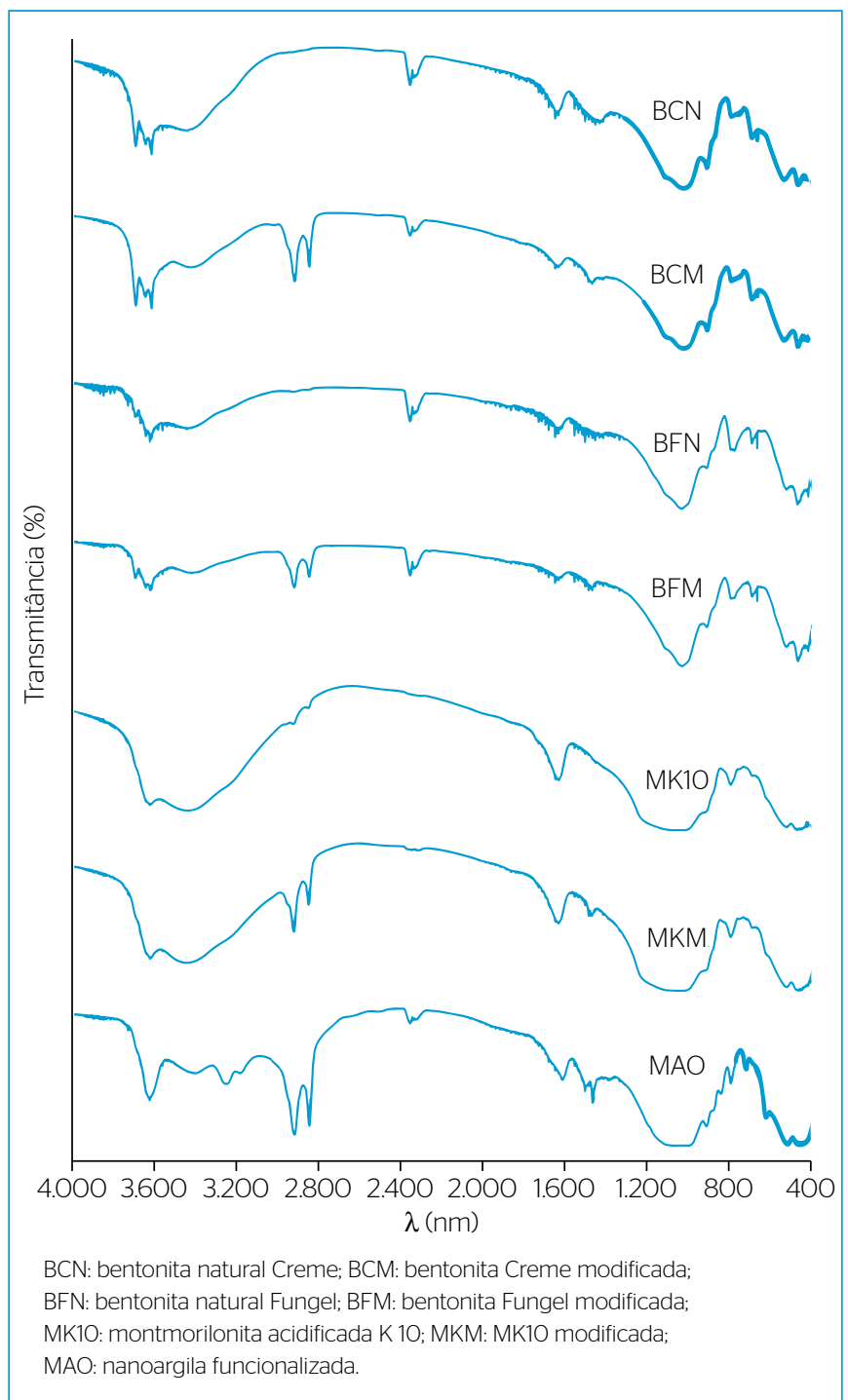

Figura 2 - Espectros de infravermelho médio das argilas BCN, BCM, BFN BFM, MK10, MKM e MAO avaliadas neste estudo.

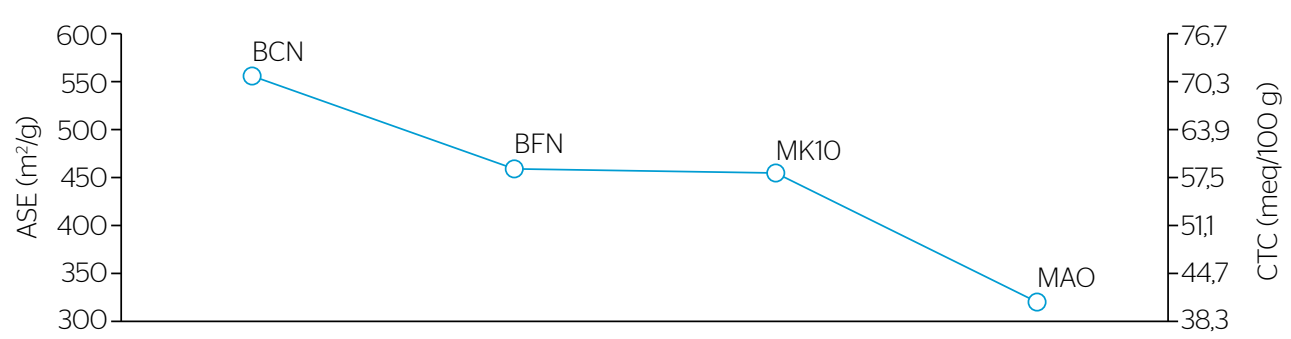

BCN: bentonita natural Creme; BFN: bentonita natural Fungel; MK1O: montmorilonita acidificada K 10; MAO: nanoargila funcionalizada.

Figura 1 - Valores de área superficial específica e capacidade de troca catiônica das argilas BCN, BFN, MK10 e MAO avaliadas neste estudo. 


\section{Experimentos de adsorção}

\section{Testes preliminares de adsorção de nitrato nas argilas e na resina}

Os resultados dos testes preliminares com as argilas naturais e modificadas (BCN, BFN, BCM, BFM, MK10 e MKM) e com a RAC estão mostrados no diagrama da Figura 3.

Eles indicam baixa afinidade relativa das argilas estudadas com o nitrato em solução aquosa, traduzida em percentuais de remoção bem abaixo do esperado, mesmo para as argilas modificadas, as quais obtiveram resultados menos significativos do que as reportadas por Bhardwaj et al. (2012) e Bagherifam et al. (2014). Esse fato seria esperado caso não ocorresse a organofilização das argilas, no entanto tal modificação é confirmada nos espectros de infravermelho médio mostrados na Figura 2 e já discutidos.

Quanto à resina aniônica, é nítida sua elevada eficiência na remoção de nitrato, com percentuais superiores a 96\%, os quais são relativamente muito superiores aos apresentados pelas argilas.

Ademais, entre as argilas estudadas, a MAO revelou-se a melhor em termos de remoção do íon contaminante, obtendo-se nesses testes preliminares percentuais de remoção de até $45 \%$. A remoção de nitrato nas demais argilas foi inferior a $20 \%$, inclusive aquelas modificadas com HDTMA, fato surpreendente e que deve ser mais bem estudado, já que não forneceram remoções de nitrato comparáveis com as reportadas na literatura, apresentando-se também inferiores à argila acidificada MK10 nesse aspecto. Portanto, a argila MAO, que demonstrou maior afinidade para adsorção do ânion nitrato, foi selecionada para estudos mais detalhados, tais como a influência da dosagem do adsorvente, a cinética e o equilíbrio de adsorção. Para fins de comparação,

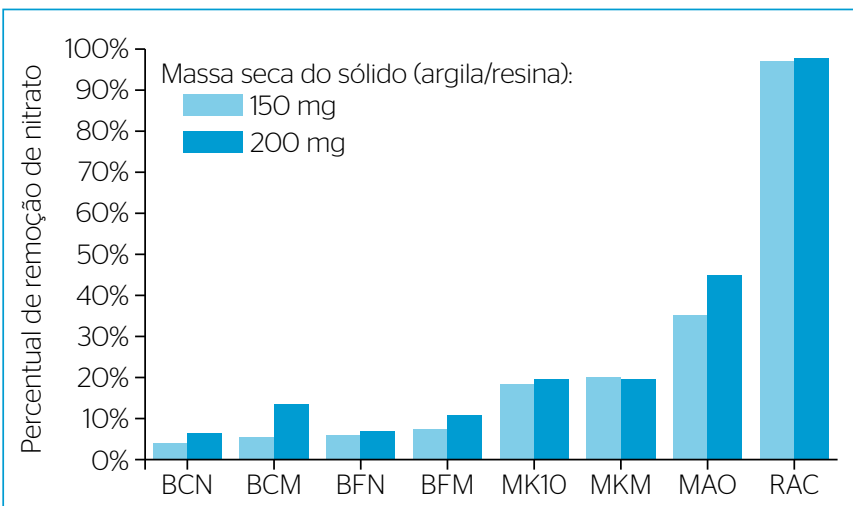

$\mathrm{BCN}$ : bentonita natural Creme; $\mathrm{BCM}$ : bentonita Creme modificada BFN: bentonita natural Fungel; BFM: bentonita Fungel modificada; MK10: montmorilonita acidificada K 10; MKM: MK10 modificada; MAO: nanoargila funcionalizada; RAC: resina de troca aniônica comercial A52OE.

Figura 3 - Percentual de remoção do íon nitrato em solução aquosa nas argilas e na resina avaliadas para concentração inicial de nitrato de $20 \mathrm{mg} \mathrm{N}-\mathrm{NO}_{3} \mathrm{~L}^{-1} \mathrm{e}$ massas de adsorvente de 150 e $200 \mathrm{mg}$. Tempo de contato de 72 horas. a resina aniônica RAC também foi avaliada em condições equivalentes a esses testes adsortivos na remoção de nitrato. Deve ser mencionado também que argilas com maiores áreas superficiais obtiveram menores remoções de nitrato, evidenciando que a natureza da funcionalização superficial da argila é determinante no processo de adsorção desse íon.

\section{Efeito da dosagem do adsorvente}

Os resultados obtidos nessa etapa estão mostrados na Figura 4. Com o aumento da massa seca da argila organofílica $\mathrm{MAO}$ e da resina aniônica RAC no meio, de 50 a $300 \mathrm{mg}\left(1,25\right.$ a 7,5 $\left.\mathrm{g} \mathrm{L}^{-1}\right)$, observou-se aumento contínuo na remoção de nitrato por ambos os materiais. Isso ocorre em razão da maior disponibilidade de sítios de interação presentes neles.

Adicionalmente, é possível perceber que, na faixa considerada de valores de massa de sólido, o aumento da remoção de nitrato pela MAO dá-se de forma mais proeminente que na RAC, haja vista que o gradiente de concentração de nitrato entre as fases líquida e sólida no sistema de troca iônica torna-se progressivamente menor que no sistema adsortivo com a MAO, em virtude dos residuais mais baixos de nitrato com a resina, à medida que a massa de sólido aumenta. Os resultados observados para a RAC na faixa de concentrações de 1,25 a 2,5 $\mathrm{g} \mathrm{L}^{-1}$ (50 a 100 mg de massa seca em $40 \mathrm{~mL}$ de solução) são comparáveis àqueles obtidos por Nur et al. (2015), os quais obtiveram remoções de 75 a $86 \%$ para concentrações de resina variando de 1,0 a 3,0 $\mathrm{g} \mathrm{L}^{-1}$.

Assim, considerando que nesses ensaios uma concentração de MAO de $5 \mathrm{~g} \mathrm{~L}^{-1}$ (200 mg de massa) fornece remoções de nitrato superiores a

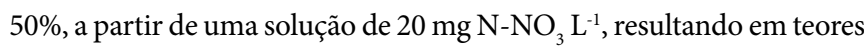
residuais aceitáveis de nitrato em água para fins de potabilidade (BRASIL, 2011), estabeleceu-se utilizar nos demais experimentos de adsorção esse valor de massa de MAO. Também, para fins de comparação, a mesma concentração de $5 \mathrm{~g} \mathrm{~L}^{-1}$ de RAC foi utilizada em testes adsortivos.

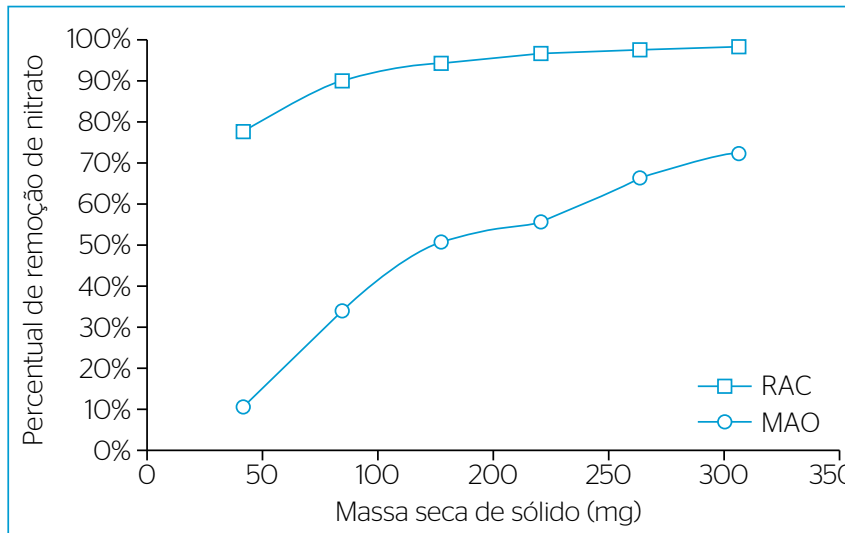

RAC: resina de troca aniônica comercial A520E;

$\mathrm{MAO}$ : nanoargila funcionalizada.

Figura 4 - Percentual de remoção de nitrato usando diferentes massas da MAO e da RAC. Volume e concentração da solução adsortiva: $40 \mathrm{~mL}$ e $20 \mathrm{mg} \mathrm{N}-\mathrm{NO}_{3} \mathrm{~L}^{-1}$, respectivamente. Tempo de contato de 24 horas. 


\section{Dados cinéticos}

As curvas cinéticas experimentais obtidas neste estudo, junto ao modelo de PSO ajustado a elas, estão apresentadas no diagrama da Figura 5. Os valores dos parâmetros dos modelos PPO e PSO ajustados aos dados experimentais, bem como os coeficientes de determinação e os desvios relativos médios para o ajuste, são mostrados na Tabela 1 .

Inicialmente, é possível afirmar, a partir dos dados cinéticos determinados, que, nas condições dos ensaios, o tempo de equilíbrio

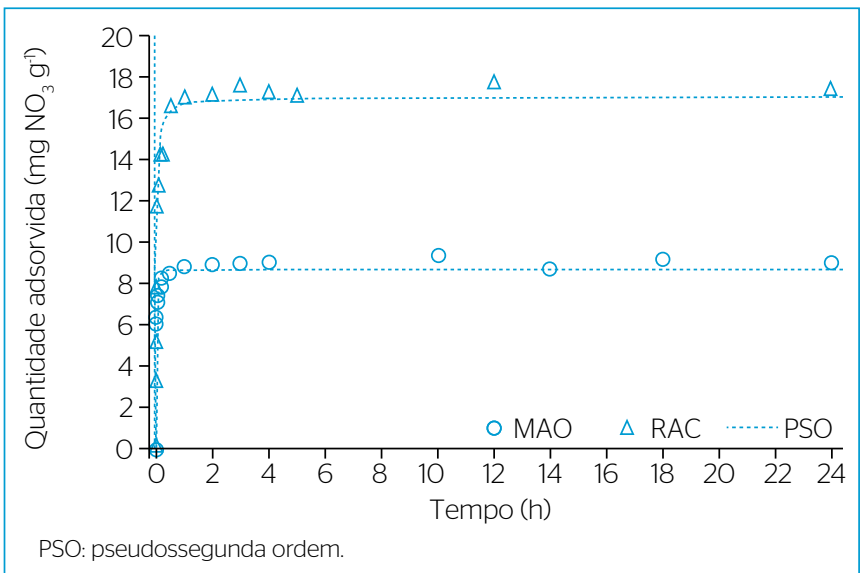

Figura 5 - Curvas cinéticas de adsorção em fase aquosa de nitrato em nanoargila funcionalizada (MAO) e em resina de troca aniônica comercial A520E (RAC). Volume e concentração inicial da solução sintética de nitrato: $40 \mathrm{~mL}$ e $20 \mathrm{mg} \mathrm{N}-\mathrm{NO}_{3} \mathrm{~L}^{-1}\left(88,6 \mathrm{mg} \mathrm{NO}_{3} \mathrm{~L}^{-1}\right)$, respectivamente. Concentração adsorvente de $5 \mathrm{~g} \mathrm{~L}^{-1}$. $\mathrm{pH}$ e temperatura: 7,0 e $25^{\circ} \mathrm{C}$, respectivamente. Agitação orbital de $240 \mathrm{rpm}$. Os símbolos no gráfico são os dados experimentais. As linhas tracejadas correspondem ao modelo PSO ajustado aos dados.

Tabela 1 - Valores dos parâmetros dos modelos de pseudoprimeira ordem e pseudossegunda ordem ajustados aos dados experimentais cinéticos para os sólidos (MAO e RAC) a $25^{\circ} \mathrm{C}$, agitação orbital de 240 rpm e pH 7,0, e estatísticas (coeficientes de determinação e desvios relativos médios) determinadas para os correspondentes ajustes.

\begin{tabular}{|c|c|c|c|c|}
\hline Sólido & Modelo & Parâmetros* & $\mathrm{R}^{2}$ & $\Delta_{\mathrm{r}}(\%)$ \\
\hline \multirow{4}{*}{ MAO } & \multirow{2}{*}{ PPO } & $\mathrm{q}_{\mathrm{e}, 1}=(8,42 \pm 0,23) \mathrm{mg} \mathrm{NO}_{3} \mathrm{~g}^{-1}$ & \multirow{2}{*}{0,8488} & \multirow{2}{*}{9,2} \\
\hline & & $\mathrm{k}_{1}=(3,45 \pm 0,77) \mathrm{min}^{-1}$ & & \\
\hline & \multirow{2}{*}{ PSO } & $\mathrm{q}_{\mathrm{e}, 2}=(8,64 \pm 0,18) \mathrm{mg} \mathrm{NO}_{3} \mathrm{~g}^{-1}$ & \multirow{2}{*}{0,9262} & \multirow{2}{*}{3,1} \\
\hline & & $\mathrm{k}_{2}=(0,64 \pm 0,15) \mathrm{g} \mathrm{mg} \mathrm{NO}_{3}{ }^{-1} \mathrm{~min}^{-1}$ & & \\
\hline \multirow{4}{*}{ RAC } & \multirow{2}{*}{ PPO } & $\mathrm{q}_{\mathrm{e}, 1}=(16,32 \pm 0,41) \mathrm{mg} \mathrm{NO}_{3} \mathrm{~g}^{-1}$ & \multirow{2}{*}{0,9463} & \multirow{2}{*}{8,7} \\
\hline & & $k_{1}=(0,61 \pm 0,09) \mathrm{min}^{-1}$ & & \\
\hline & \multirow{2}{*}{ PSO } & $\mathrm{q}_{\mathrm{e}, 2}=(17,01 \pm 0,24) \mathrm{mg} \mathrm{NO}_{3} \mathrm{~g}^{-1}$ & \multirow{2}{*}{0,9854} & \multirow{2}{*}{6,2} \\
\hline & & $\mathrm{k}_{2}=(0,05 \pm 0,005) \mathrm{g} \mathrm{mg} \mathrm{NO}_{3}{ }^{-1} \mathrm{~min}^{-1}$ & & \\
\hline
\end{tabular}

$\mathrm{R}^{2}$ : coeficiente de determinação; $\Delta$ : desvio relativo médio; MAO: nanoargila funcionalizada; RAC: resina de troca aniônica comercial A52OE; PPO: pseudoprimeira ordem; PSO: pseudossegunda ordem; $\mathrm{q}_{\mathrm{e}, \mathrm{i}}$ teor de nitrato sorvido no equilíbrio no modelo cinético de pseudoprimeira ordem; $\mathrm{k}_{\text {: }}$ constantes de velocidade no modelo cinético de pseudoprimeira ordem; $\mathrm{q}_{\mathrm{e} 2}$ : teor de nitrato sorvido no equilíbrio no modelo cinético de pseudoprimeira ordem; $\mathrm{k}_{2}$ : constantes de velocidade no modelo cinético de pseudossegunda ordem; *o erro padrão de cada estimativa de parâmetro é mostrado após o símbolo \pm (à direita). é atingido em aproximadamente 120 minutos, com percentuais de remoção de nitrato de 53 e 97\% para a MAO e para a RAC, respectivamente. Nur et al. (2015) também observaram tempos de equilíbrio de 2 horas para a adsorção de nitrato na RAC, em condições próximas às aqui utilizadas.

Em relação aos dois modelos cinéticos testados, ambos foram satisfatórios. Os estudos cinéticos de Nur et al. (2015) com a RAC também mostraram que o PPO e o PSO se adequam bem ao sistema com a resina. Contudo, pode-se afirmar que, de maneira geral, o modelo que melhor se ajusta a ambos os sistemas cinéticos aqui estudados, com maiores $\mathrm{R}^{2}$ e menores $\Delta_{r}$, é o modelo de PSO, podendo ser usado em cálculos de projeto, no contexto das condições operacionais testadas. Vale a pena comentar que a boa representação dos dados cinéticos com tais modelos, especialmente com o PSO, é ressaltada por Tien e Ramarao (2017).

Os parâmetros cinéticos determinados demonstram que a velocidade de adsorção na argila é maior que na resina, haja vista as maiores constantes cinéticas $\left(\mathrm{k}_{1} \mathrm{e} \mathrm{k}_{2}\right)$ obtidas para a MAO. Entretanto, a capacidade de remoção de nitrato da RAC no equilíbrio, notadamente superior à da argila investigada, nas condições experimentais consideradas, reforça o entendimento de que a resina usada ainda é mais eficiente na remoção de nitrato que a argila selecionada, com percentuais superiores a $95 \%$ para a RAC contra percentuais de remoção menores que $60 \%$ para a argila, após o tempo de equilíbrio. Estudos mais aprofundados devem permitir uma otimização das condições operacionais em que a MAO possa se tornar mais competitiva em relação à RAC.

\section{Isotermas na adsorção}

As isotermas experimentais de adsorção obtidas para a MAO e a RAC, nas temperaturas 25,35 e $45^{\circ} \mathrm{C}$, junto ao MIF ajustado aos dados, estão mostradas no diagrama da Figura 6. Os valores dos coeficientes dos modelos MIF e MIL ajustados, como também os correspondentes $\mathrm{R}^{2}$ e $\Delta_{r}$ dos ajustes realizados, estão reportados na Tabela 2.

A partir das curvas de equilíbrio mostradas fica evidente que a capacidade adsortiva da argila selecionada é bem inferior que a apresentada pela resina, que é industrialmente usada na remoção de nitrato de águas. Estudos complementares devem ser conduzidos com o intuito de avaliar a eficiência de ambos os adsorventes na presença de outros ânions, tais como cloreto e sulfato que, em geral, competem com o nitrato no processo estudado, diminuindo a eficiência de remoção desse contaminante com esses adsorventes.

Dos modelos de equilíbrio avaliados, o MIF foi o que melhor representou os sistemas estudados, já que forneceu os menores $\Delta_{\mathrm{r}} \mathrm{e}$, em geral, os maiores valores de $\mathrm{R}^{2}$, sugerindo que haja uma heterogeneidade superficial não negligenciável nos adsorventes. A despeito disso, os coeficientes do modelo de Langmiur podem ser avaliados e utilizados no maior entendimento do processo, haja vista que esse 
modelo não produz desvios muito elevados em toda a faixa de dados experimentais. Os maiores desvios são encontrados para ambos os modelos na região de baixas concentrações de nitrato.

Os valores de $\mathrm{n}$, maiores que a unidade, indica adsorção favorável do nitrato em ambos os materiais nas condições avaliadas, fato também observado em outros estudos, tanto com a RAC (NUR et al., 2012) como com argilas organofuncionalizadas (BHARDWAJ et al., 2012; BAGHERIFAM et al., 2014). Ressalta-se que as boas capacidades máximas de adsorção estimadas pelo MIL para a adsorção de nitrato a $25^{\circ} \mathrm{C}$ na MAO são da mesma ordem de grandeza dos valores encontrados nos estudos de Bagherifam et al. (2014) para outra montmorilonita organofílica modificada, consideradas as diferenças nas condições experimentais utilizadas nesses estudos. Os valores determinados para a remoção de nitrato com a RAC também são próximos daqueles obtidos por Nur et al. (2015) para a mesma resina aniônica.

Ademais, o emprego da Equação 8, obtida da combinação das Equações 6 e 7, no ajuste linearizado dos dados apresentados na Figura 7, obtidos na modelagem dos dados de equilíbrio com o MIL, tomando-se os valores de $\mathrm{k}_{L}$ em L mol${ }^{-1}$, fornecem as propriedades termodinâmicas mostradas na Tabela 3.

$\operatorname{Ln}\left(k_{L}\right)=-\frac{H^{\circ}}{R T}+\frac{S^{\circ}}{R}$

Os valores de $\Delta \mathrm{G}^{\circ}$ estimados confirmam a adsorção de nitrato na argila selecionada e na resina como um processo espontâneo na faixa de temperaturas considerada no estudo. Os valores obtidos de $\Delta \mathrm{H}^{\circ}$,

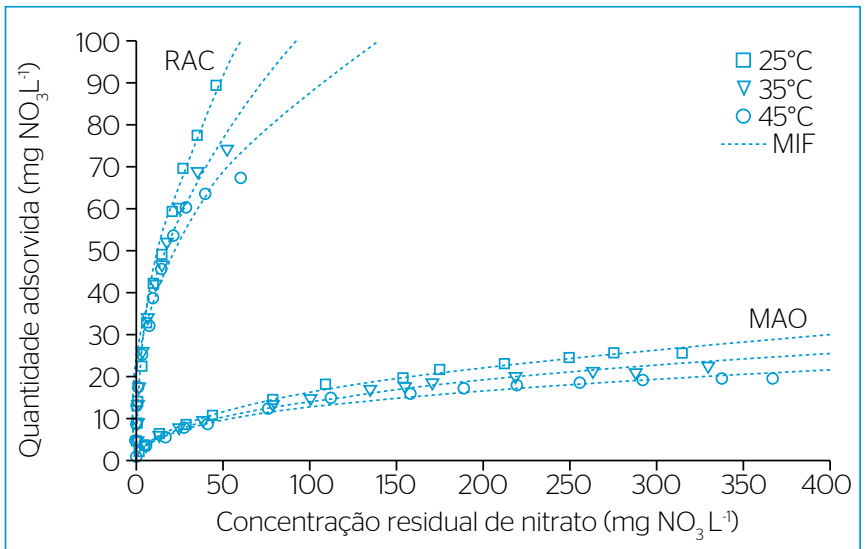

RAC: resina de troca aniônica comercial A520E.

Figura 6 - Isotermas de equilibrio de adsorção em fase aquosa de nitrato em nanoargila funcionalizada (MAO). Volume da solução sintética de nitrato de $40 \mathrm{~mL}$ e concentrações iniciais de nitrato na faixa de concentração de 5 a $100 \mathrm{mg} \mathrm{N}^{-N} \mathrm{~L}_{3}^{-1}$ (22 a $\left.443 \mathrm{mg} \mathrm{NO}_{3} \mathrm{~L}^{-1}\right)$. Agitação orbital de $240 \mathrm{rpm}$. Concentração do adsorvente: $5 \mathrm{~g} \mathrm{~L}^{-1}$. $\mathrm{pH}$ e temperatura do meio: 7,0 e $25^{\circ} \mathrm{C}$, respectivamente. Tempo mínimo de equilíbrio: 2 horas. Os símbolos no gráfico são os dados experimentais. As linhas tracejadas correspondem ao modelo de isoterma de Freundlich (MIF) ajustado aos dados. bem menores que $40 \mathrm{~kJ} \mathrm{~mol}^{-1}$, sugerem que a adsorção entre o íon e os adsorventes é de natureza física (ARAÚJO et al., 2009). Os valores positivos de $\Delta \mathrm{S}^{\circ}$ refletem a boa afinidade desses adsorventes em relação ao nitrato (BHARDWAJ et al., 2012). Os maiores valores de $\Delta \mathrm{H}^{\circ}$ e de $\Delta \mathrm{S}^{\circ}$ na $\mathrm{RAC}$ em relação à $\mathrm{MAO}$ corroboram a maior eficiência da primeira na remoção do íon contaminante estudado.

\section{CONCLUSÕES}

Neste estudo, uma nanoargila montmorilonita aminofuncionalizada comercial demonstrou ser a mais eficiente, mesmo com a menor área

Tabela 2 - Valores dos parâmetros dos modelos de isoterma modelo de isoterma de Freundlich (MIF) e modelo de isoterma de Langmuir (MIL) ajustados aos dados experimentais de equilíbrio para os adsorventes nanoargila funcionalizada (MAO) e resina de troca aniônica comercial A520E (RAC) nas temperaturas 25,35 e $45^{\circ} \mathrm{C}$ e estatísticas determinadas para os correspondentes ajustes.

\begin{tabular}{|c|c|c|c|c|c|}
\hline Sólido & $\begin{array}{l}\text { Temp. } \\
\left({ }^{\circ} \mathrm{C}\right)\end{array}$ & Modelo & Parâmetros* & $\mathrm{R}^{2}$ & $\begin{array}{c}\Delta \\
\text { (\%) }\end{array}$ \\
\hline \multirow{12}{*}{ MAO } & \multirow{4}{*}{25} & \multirow{2}{*}{ MIF } & $K_{F}=(1,93 \pm 0,40) m g^{0.539} g^{-1} L^{-0,461}$ & \multirow{2}{*}{0,9925} & \multirow{2}{*}{5,3} \\
\hline & & & $n=2,17 \pm 0,19$ & & \\
\hline & & \multirow{2}{*}{ MIL } & $k_{L}=(0,0113 \pm 0,0033) L m^{-1}$ & \multirow{2}{*}{0,9858} & \multirow{2}{*}{14} \\
\hline & & & $\mathrm{q}_{\mathrm{m}}=(32,68 \pm 3,30) \mathrm{mg} \mathrm{g}^{-1}$ & & \\
\hline & \multirow{4}{*}{35} & \multirow{2}{*}{ MIF } & $k_{F}=(2,12 \pm 0,39) m g^{0.587} g^{-1} L^{-0.413}$ & \multirow{2}{*}{0,9901} & \multirow{2}{*}{5,2} \\
\hline & & & $n=2,42 \pm 0,21$ & & \\
\hline & & \multirow{2}{*}{ MIL } & $\mathrm{K}_{\mathrm{L}}=(0,0146 \pm 0,0038) \mathrm{L} \mathrm{mg}^{-1}$ & \multirow{2}{*}{0,9822} & \multirow{2}{*}{8,0} \\
\hline & & & $\mathrm{a}_{\mathrm{m}}=(25,95 \pm 2,10) \mathrm{mg} \mathrm{g}^{-1}$ & & \\
\hline & \multirow{4}{*}{45} & \multirow{2}{*}{ MIF } & $k_{F}=(2,19 \pm 0,53) m g^{0,618} \mathrm{~g}^{-1} \mathrm{~L}^{-0,382}$ & \multirow{2}{*}{0,9841} & \multirow{2}{*}{9,4} \\
\hline & & & $n=2,62 \pm 0,31$ & & \\
\hline & & \multirow{2}{*}{ MIL } & $k_{L}=(0,0168 \pm 0,0038) L_{m g}^{-1}$ & \multirow{2}{*}{0,9888} & \multirow{2}{*}{16} \\
\hline & & & $\mathrm{q}_{\mathrm{m}}=(22,61 \pm 1,40) \mathrm{mg} \mathrm{g}^{-1}$ & & \\
\hline \multirow{12}{*}{ RAC } & \multirow{4}{*}{25} & \multirow{2}{*}{ MIF } & $\mathrm{k}_{\mathrm{F}}=(14,4 \pm 1,7) \mathrm{mg}^{0.526} \mathrm{~g}^{-1} \mathrm{~L}^{-0.474}$ & \multirow{2}{*}{ 0,9945 } & \multirow{2}{*}{7,8} \\
\hline & & & $n=2,11 \pm 0,16$ & & \\
\hline & & \multirow{2}{*}{ MIL } & $k_{L}=(0,0653 \pm 0,040) L \mathrm{mg}^{-1}$ & \multirow{2}{*}{0,9512} & \multirow{2}{*}{28} \\
\hline & & & $\mathrm{q}_{\mathrm{m}}=(111,6 \pm 27,8) \mathrm{mg} \mathrm{g}^{-1}$ & & \\
\hline & \multirow{4}{*}{35} & \multirow{2}{*}{ MIF } & $\mathrm{k}_{\mathrm{F}}=(15,2 \pm 1,9) \mathrm{mg}^{0.583} \mathrm{~g}^{-1} \mathrm{~L}^{-0.417}$ & \multirow{2}{*}{0,9902} & \multirow{2}{*}{8,9} \\
\hline & & & $n=2,40 \pm 0,23$ & & \\
\hline & & MII & $\mathrm{K}_{\mathrm{L}}=(0,102 \pm 0,046) \mathrm{L} \mathrm{mg}^{-1}$ & 653 & 27 \\
\hline & & & $\mathrm{q}_{\mathrm{m}}=(84,75 \pm 13,2) \mathrm{mg} \mathrm{g}^{-1}$ & & \\
\hline & & 1 & $\mathrm{~K}_{\mathrm{F}}=(16,1 \pm 2,8) \mathrm{mg}^{0.630} \mathrm{~g}^{-1} \mathrm{~L}^{-0.370}$ & 20 & 12 \\
\hline & & IVIII & $n=2,70 \pm 0,38$ & (1) & IJ \\
\hline & & & $\mathrm{K}_{\mathrm{L}}=(0,126 \pm 0,046) \mathrm{L} \mathrm{mg}^{-1}$ & & \\
\hline & & TVIIL & $\mathrm{q}_{\mathrm{m}}=(74,96 \pm 8,42) \mathrm{mg} \mathrm{g}^{-1}$ & 40 & \\
\hline
\end{tabular}

$\mathrm{R}^{2}$ : coeficiente de determinação; $\Delta_{r}$ : desvio relativo médio; $\mathrm{k}_{\mathrm{f}}$ e n: coeficientes empíricos do modelo de isoterma de Freundlich; $k_{\llcorner}$: constante de afinidade do modelo de isoterma de Langmuir; $\mathrm{q}_{\mathrm{m}}$ : capacidade máxima de adsorção em monocamada do modelo de isoterma de Langmuir; *o erro padrão de cada estimativa de parâmetro é mostrado após o símbolo \pm (à direita). 


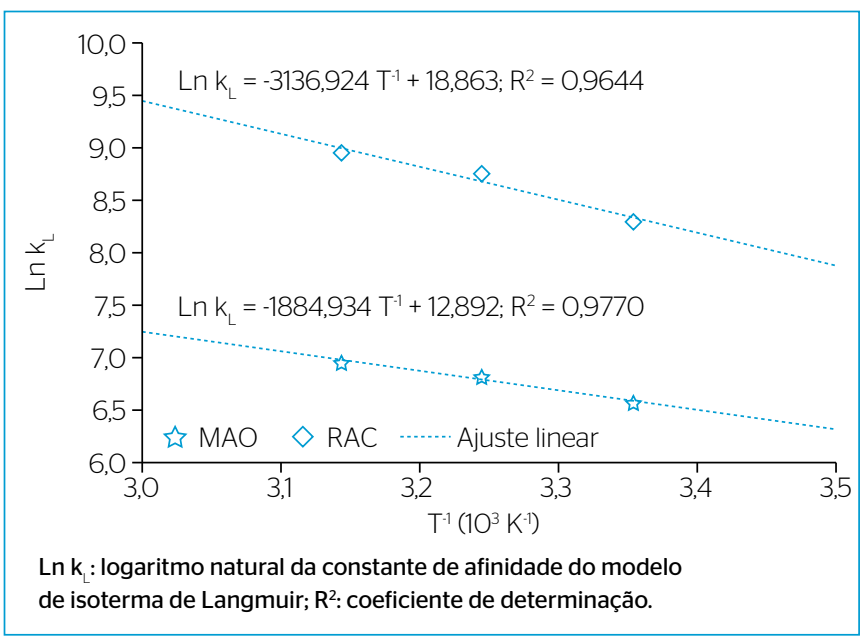

Figura 7 - Ajuste dos dados linearizados de $k_{\llcorner}$em função da temperatura termodinâmica na adsorção de nitrato nos adsorventes nanoargila funcionalizada (MAO) e resina de troca aniônica comercial A520E (RAC) e nas condições experimentais ensaiadas.
Tabela 3 - Valores dos parâmetros termodinâmicos determinados a partir dos parâmetros $k_{L}$ do modelo de isoterma de Langmuir (MIL) ajustados aos dados experimentais de equilíbrio para os sólidos (MAO e RAC) nas temperaturas 25,35 e $45^{\circ} \mathrm{C}$ e estatísticas (coeficientes de determinação e desvios relativos médios) determinadas para os correspondentes ajustes.

\begin{tabular}{|c|c|c|c|c|c|}
\hline Sólido & $\begin{array}{l}\text { Temp. } \\
\left({ }^{\circ} \mathrm{C}\right)\end{array}$ & $\begin{array}{c}\mathrm{k}_{\mathrm{L}} \\
\left(\mathrm{L} \mathrm{mol}^{-1}\right)\end{array}$ & $\begin{array}{c}\Delta \mathrm{G}^{\circ} \\
\left(\mathrm{kJ} \mathrm{mol} \mathrm{l}^{-1}\right)\end{array}$ & $\begin{array}{c}\Delta \mathrm{H}^{\circ} \\
\left(\mathrm{kJ} \mathrm{mol}^{-1}\right)\end{array}$ & $\begin{array}{c}\Delta \mathrm{S}^{\circ} \\
\left(\mathrm{J} \mathrm{mol} \mathrm{l}^{-1} \mathrm{~K}^{-1}\right)\end{array}$ \\
\hline \multirow{3}{*}{ MAO } & 25 & 701,22 & $-16,24$ & \multirow{3}{*}{15,67} & \multirow{3}{*}{107,18} \\
\hline & 35 & 907,06 & $-17,45$ & & \\
\hline & 45 & 1042,22 & $-18,38$ & & \\
\hline \multirow{3}{*}{ RAC } & 25 & 4047,36 & $-20,59$ & \multirow{3}{*}{26,08} & \multirow{3}{*}{156,82} \\
\hline & 35 & 6349,42 & $-22,43$ & & \\
\hline & 45 & 7823,16 & $-23,71$ & & \\
\hline
\end{tabular}

$\mathrm{K}_{1}$ : constante de afinidade do modelo de isoterma de Langmuir; $\Delta \mathrm{G}^{\circ}$ : variação de energia livre de Gibbs padrão; $\Delta \mathrm{H}^{\circ}$ : variação de entalpia padrão; $\Delta \mathrm{S}^{\circ}$ : variação de entropia padrão; MAO: nanoargila funcionalizada; RAC: resina de troca aniônica comercial A520E; *o erro padrão de cada estimativa de parâmetro é mostrado após o símbolo \pm (à direita) superficial, entre as demais testadas, na remoção de nitrato por adsorção, conquanto não tenha sido superior em eficiência a uma resina aniônica comercialmente usada para esse fim.

Os dados cinéticos e de equilíbrio determinados e modelados mostram que a adsorção na faixa de temperatura entre 25 e $45^{\circ} \mathrm{C}$ é espontânea e favorável tanto para a resina como para a nanoargila. Os modelos mais representativos para a cinética e o equilíbrio dos sistemas estudados foram, respectivamente, o de PSO e o MIF. O equilíbrio dos sistemas estudados é atingido em, aproximadamente, 2 horas.
As propriedades termodinâmicas obtidas também evidenciam a ocorrência de uma fisissorção com muito boa afinidade de ambos os adsorventes com o íon nitrato.

\section{FONTE DE FINANCIAMENTO}

Coordenação de Aperfeiçoamento de Pessoal de Nível Superior (CAPES), Conselho Nacional de Desenvolvimento Científico e Tecnológico (CNPq).

\section{REFERÊNCIAS}

AGUIAR, R.B.; SANTIAGO, M.M.F.; VASCONCELOS, S.M.S. (2000) Potabilidade das águas subterrâneas no litoral do município de Caucaia-Ceará. Águas Subterrâneas, supl.

ARAÚJO, A.L.P.; SILVA, M.C.C.; GIMENES, M.L.; BARROS, M.A.S.D. (2009) Estudo termodinâmico da adsorção de zinco em argila bentonita bofe calcinada. Scientia Plena, v. 5, n. 12. Disponível em: $\quad<$ https://www.scientiaplena.org.br/sp/article/view/680/350>. Acesso em: 12 set. 2017.

BAGHERIFAM,S:; KOMARNENI,S.:LAKZIAN,A.; FOTOVAT,A.; KHORASANI, R.; HUANG, W:; MA, J.; HONG, S.; CANNON, F.S.; WANG, Y. (2O14) Highly selective removal of nitrate and perchlorate by organoclay. Applied Clay Science, v. 95, p. 126-132. https://doi.org/10.1016/j.clay.2014.03.021

BEKELE, W.; FAYE, G.; FERNANDEZ, N. (2014) Removal of nitrate ion from aqueous solution by modified Ethiopian bentonite clay.
International Journal of Research in Pharmacy and Chemistry, v. 4, n. 1, p. $192-201$.

BHARDWAJ, D.; SHARMA, M.; SHARMA, P.; TOMAR, R. (2O12) Synthesis and surfactant modification of clinoptilolite and montmorillonite for the removal of nitrate and preparation of slow release nitrogen fertilizer. Journal of Hazardous Materials, v. 227228, p. 292-300. https://doi.org/10.1016/j.jhazmat.2012.05.058

BRASIL. (2011) Ministério da Saúde. Portaria no 2.914, de 12 de dezembro de 2011. Dispõe sobre os procedimentos de controle e vigilância da qualidade da água para consumo humano e seu padrão de potabilidade. Secretaria de Vigilância em Saúde. Diário Oficial [da] República Federativa do Brasil, Brasília, seção 1, p. 39-46. caracterização de argilas organofílicas do tipo BOFE. In: CONGRESSO 
BRASILEIRO DE ENGENHARIA QUIIMICA EM INICIAÇÃO CIENTÍFICA, 8., 2009, Uberlândia. Anais... Rio de Janeiro: ABES.

COSTA, C.L;; LIMA, R.F.; PAIXÃO, G.C.; PANTOJA, L.D.M. (2O12) Avaliação da qualidade das águas subterrâneas em poços do estado do Ceará, Brasil. Semina: Ciências Biológicas e da Saúde, v. 33, n. 2, p. 171-180. http://dx.doi.org/10.5433/1679-0367.2012v33n2p171

DO, D.D. (1998) Adsorption analysis: equilibria and kinetics. Londres: Imperial College Press. v. 2. (Series on Chemical Engineering).

DUARTE-NETO, J.F; CARTAXO, J.M.; NEVES, G.A.; MENEZES, R.R. (2O14) Processos de adsorção de corantes em argilas esmectíticas: uma revisão. Revista Eletrônica de Materiais e Processos, v. 9, n. 1, p. 51-59.

EATON, A.D.; CLESCERI, L.S.; RICE, E.W.; GREENBERG, A.B. (Orgs.). (2005) Standard methods for examination of water and wastewater. 21a. ed. Washington, D.C.: American Public Health Association.

FREITAS, I.: SALES, M.V. (2O14) Avaliação de resina básica fortemente aniônica para remoção de nitrato através de ensaio em ETA piloto. In: SIMPÓSIO ITALO-BRASILEIRO DE ENGENHARIA SANITÁRIA E AMBIENTAL, 12., 2014, Natal. Anais... Rio de Janeiro: Associação Brasileira de Engenharia Sanitária e Ambiental.

GOMES, M.A.F; BARIZON, R.R.M. (2014) Panorama da contaminação ambiental por agrotóxicos enitrato de origem agrícola no Brasil: cenário 1992/2011. Jaguariúna: Embrapa Meio Ambiente. 35 p. (Documentos 98).

HAMEED, B.H.; AHMAD, A.A.; AZIZ, N. (2007) Isotherms, kinetics and thermodynamics of acid dye adsorption on activated palm ash. Chemical Engineering Journal, v. 133, n. 1-3, p. 195-203. http:// dx.doi.org/10.1016/j.cej.2007.01.032

HARO, N.K. (2O11) Avaliação da remoção de íns nitrato utilizando carvão ativado modificado com diferentes reagentes com o sólido sorvente. 44 f. Monografia (Graduação em Engenharia Química) Universidade Federal do Rio Grande do Sul, Porto Alegre.

HE, J.; HONG, S.; ZHANG, L.; GAN, F.; HO, Y.S. (2O10) Equilibrium and thermodynamic parameters of adsorption of methylene blue onto rectorite. Fresenius Environmental Bulletin, v. 19, n. 11, p. 2651-2656.

HELLER-KALLAI, L. (2001) Protonation-deprotonation of dioctahedral smectites. Applied Clay Science, v. 20, n. 1-2, p. 27-38. https://doi. org/10.1016/S0169-1317(O1)00038-2

HO, Y.S.; MCKAY, G. (1999) Comparative sorption kinetic studies of dye and aromatic compounds onto fly ash. Journal of Environmental Science and Health, Part A: Toxic/Hazardous Substances and Environmental Engineering, v. 34, n. 5, p. 1179-1204. https://doi.org/10.1080/10934529909376889

LAGERGREN, S. (1898) Zur theorie der sogenannten adsorption gelöster stoffe. Kungliga Svenska Vetenskapsakademiens, Handlingar, v. 24, n. 4, p. 1-39.

LI, J.; LI, Y.; MENG, Q. (2010) Removal of nitrate by zero-valent iron and pillared bentonite. Journal of Hazardous Materials, v. 174, n. 1-3, p. 188-193. https://doi.org/10.1016/j.jhazmat.2009.09.035
MENA-DURAN, C.J; KOU, M.S.; LOPEZ, T; AZAMAR-BARRIOS, J.A.; AGUILAR, D.H.; DOMINGUEZ, M.I.; ODRIOZOLA, J.A.; QUINTANA, P. (2007) Nitrate removal using natural clays modified by acid thermoactivation. Applied Surface Science, v. 253, n. 13, p. 57625766. https://doi.org/10.1016/j.apsusc.2006.12.103

MILMILE, S.N.; PANDE, J.V.; KARMAKAR, S.; BANSIWAL, A. CHAKRABARTI, T.; BINIWALE, R.B. (2011) Equilibrium isotherm and kinetic modeling of the adsorption of nitrates by anion exchange Indion NSSR resin. Desalination, v. 276, n. 1-3, p. 38-44. http://dx.doi. org/10.1016/j.desal.2011.03.015

MORITA, R.Y.; BARBOSA, R.V.; KLOSS, J.R. (2015) Caracterização de bentonitas sódicas: efeito do tratamento com surfactante orgânico livre de sal de amônio. Revista Virtual de Química, v. 7, n. 4, p. 12861298. http://dx.doi.org/10.5935/1984-6835.20150071

NASCIMENTO, R.F.; LIMA, A.C.A.; VIDAL, C.B.; MELO, D.Q.; RAULINO, G.S.C. (2014) Adsorção: aspectos teóricos e aplicações ambientais. Fortaleza: Imprensa Universitária.

NUR, T.; JOHIR, M.A.H.; LOGANATHAN, P.; VIGNESWARAN, S.; KANDASAMY, J. (2012) Effectiveness of purolite A500PS and A520E ion exchange resins on the removal of nitrate and phosphate from synthetic water. Desalination and Water Treatment, v. 47, n. 1-3, p. 50-58. https://doi.org/10.1080/194439 94.2012.696424

NUR, T.; SHIM, W.G.; LOGANATHAN, P.; VIGNESWARAN, S.; KANDASAMY, J. (2015) Nitrate removal using Purolite A52OE ion exchange resin: batch and fixed-bed column adsorption modelling. International Journal of Environmental Science and Technology. v. 12, n. 4, p. 1311-1320. http://dx.doi.org/10.1007/s13762-014-0510-6

PAIVA, L.B.; MORALES, A.R.; DÍAZ, F.R.V. (2008) Argilas organofilicas: características, metodologias de preparação, compostos de intercalação e técnicas de caracterização. Cerâmica, v. 54, n. 330, p. 213-226. http://dx.doi.org/10.1590/S0366-69132008000200012

PATRICIO, J.S. (2013) Caracterização de argilas naturais e ativadas aplicadas na clarificação de óleo de soja. Dissertação (Mestrado em Ciência e Engenharia de Materiais) - Universidade Federal de Santa Catarina, Florianópolis.

PEREIRA, J.M.J. (2014) Produção de monoglicéridos através de catalisadores de argila. Dissertação (Mestrado em Bioquímica Aplicada) - Universidade da Madeira, Funchal.

PINHEIRO, M.H.T.; LEMOS, V.P.; DANTAS, K.D.G.F; VALENTIM, T.L. (2013) Especiação e quimissorção de $\mathrm{Pb}$ (II) em rejeito de caulim. Química Nova, v. 36, n. 2, p. 272-278. http://dx.doi.org/10.1590/SO10040422013000200013

SANTAMARINA, J.C.; KLEIN, K.A.; WANG, Y.H.; PRENCKE, E. (2002) Specific surface: determination and relevance. Canadian Geotechnical Journal, v. 39, n. 1, p. 233-241. https://doi. org/10.1139/t01-077

SANTOS, P.S. (1989) Ciência e tecnologia de argilas. 2a. ed. São Paulo: Edgard Blücher. v. 1. 
SELIEM, M.K.; KOMARNENI, S.; BYRNE, T.; CANNON, F.S.; SHAHIEN, M.G.; KHALIL, A.A.; EL-GAID, I.A. (2013) Removal of nitrate by synthetic organosilicas and organoclay: kinetic and isotherm studies. Separation and Purification Technology, v. 110, p. 181-187. https://doi.org/10.1016/j.seppur.2013.03.023

SHARMA, P; KAUR, H.; SHARMA, M.; SAHORE, V. (2O11) A review on applicability of naturally availableadsorbents for the removal of hazardous dyes from aqueous waste. Environmental Monitoring and Assessment, v. 183, n. 1-4, p. 151-195. https://doi.org/10.1007/s10661-011-1914-O

SOUSA NETO, V.O. (2012) Modificação química da casca do coco bruto (Cocos Nucifera) para remoção de Cu (II) de efluente sintético e industrial: estudo de isoterma de adsorção, cinética e coluna de leito fixo. Tese (Doutorado em Engenharia Civil) - Universidade Federal do Ceará, Fortaleza, 2012.

TIEN, C.; RAMARAO, B.V. (2017) On the significance and utility of the Lagergren model and the pseudo second-order model of batch adsorption. Separation Science and Technology, v. 52, n. 6, p. 975986. https://doi.org/10.1080/01496395.2016.1274327
TORRES, R.M. (2011) Remoção biológica de nitrato em água de abastecimento humano utilizando o endocarpo de coco como fonte de carbono. 42 f. Dissertação (Mestrado em Engenharia Sanitária) - Universidade Federal do Rio Grande do Norte, Natal.

VIMONSES, V.; JIN, B.; CHOW, C.W.K.; SAINT, C. (2009) Enhancing removal efficiency of anionic dye by combination and calcinations of clay materials and calcium hydroxide. Journal of Hazardous Materials, v. 171, n. 1-3, p. 941-947. http://dx.doi. org/10.1016/j.jhazmat.2009.06.094

XI, Y.; MALLAVARAPU, M.; NAIDU, R. (2010) Preparation, characterization of surfactants modified clay minerals and nitrate adsorption. Applied Clay Science, v. 48, n. 1-2, p. 92-96. https://doi. org/10.1016/j.clay.2009.11.047

YUKSELEN, Y.; KAYA, A. (2008) Suitability of the methylene blue test for surface area, cation exchange capacity and swell potential determination of clayey soils. Engineering Geology, v. 102, n. 1 , p. 38-45. http://dx.doi.org/10.1016/j.enggeo.2008.07.002 